20-28 OSA Annual Meeting. Providence, RI. Optical Society of America, Conf. Services Dept. 2010 Massachusetts Ave., N.W. Washington, DC 20036-1023; 202-416-1980; fax 202-416-6100; e-mail confserv@osa.org. http://www.osa.org/mtg-conf.

22-27 198th Meeting of The Electrochemical Society, Phoenix, AZ. The Electrochemical Society, $10 \mathrm{~S}$. Main St. Pennington, NJ 08534-2896; 609-737-1902; fax 609-737-2743; e-mail ecs@ electrochem.org; http://www. electrochem.org/meetings/.

\section{NOVEMBER 2000}

13-14 ASTM Symposium on Marine Corrosion in Tropical Environments, Merida, Yucatan, Mexico. V. Chaker, Port Authority of NY-NJ, One World Trade Ctr. $74 W$, New York, NY 10048; 212435-5790; tax 215-435-8040.

27-1 MRS Fall Meeting, Boston, MA. Materials Research Society, 506 Keystone Drive, Warrendale, PA 15086-7573; 724-779-3003; fax 724-779-8313; http://www.mrs.org/. MRS.

JOINT MEETING ANNOUNCEMENT-
North Carolina Section of the Materials Research Society
Mid-Atlantic Region of the American Vacuum Society
Southeastern Section of the American Physical Society
November 8, 1999, Chapel Hill, North Carolina
Meeting Overview:
The annual Fall meetings of the North Carolina Section of the Materials Research Society
and the Mid-Atlantic Region of the American Vacuum Society will be held at the Sheraton
Hotel in Chapel Hill, NC. This combined meeting is being organized jointly with the 66th
Annual Meeting of the Southeastern Section of the American Physical Society (SESAPS),
which will be held November 7-9, 1999.
The Program will feature Growth, Processing and Characterization of Wide
Bandgap Materials and Smart Materials Processing.
For more information, contact: Dr. John M. Lannon, MCNC, Durnam, NC 27709; 919-248-1872; fax 919-
248-1455; lannon@mcnc.org or Dr. John J. Boland, University of North Carolina at Chapel Hill, Chapel
Hill, NC 27599-3290; 919-962-5098; fax 919-962-2388; boland@unc.edu.

\title{
CLASSIFIED
}

\section{Positions Available}

\section{ASSISTANT PROFESSOR Materials Science and Engineering}

The Department of Materials Science and Engineering at the University of Delaware is continuing to expand and invites applications for a junior faculty position in Electronic and Magnetic Materials, Polymers, Inorganic Materials, Materials Chemistry or Biomaterials/Biomimetics. The current opening is a tenure track faculty position at the Assistant Professor level. REQUIREMENTS: Ph.D. degree in Materials Science or related field, qualified to teach undergraduate and graduate courses in Materials Science and willing to develop a worldclass research program which includes collaborations with existing materials-based groups within the university and in local industry. It is anticipated that the candidate would be an effective communicator and enjoy teaching and mentoring students. Demonstrated independence in the choice of research areas as evidenced by quality publications and the submission of a clear research plan is an important part of the evaluation process. CONTACT: Send a resume, a description of proposed research and three letters of recommendation to John $F$. Raboli, Chair, Faculty Search Commitlee, Department of Materials Science and Engineering, Spencer Laboratory - Room 301, University of Delaware, Newark, DE 19716. The search committee will begin the review and processing of applications on October 15,1999 and will continue to accept applications until the position is filled.

The UNIVERSITY OF DELAWARE is an Equal Opportunity Employer which encourages applications from

Minority Group

Members and

Women.

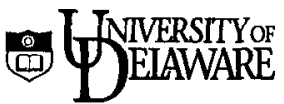

\section{TO PLACE YOUR AD \\ CONTACT MARY E. KAUFOLD TODAY!}

724-779-8312

kaufold@mrs.org

SENIOR SCIENTIST
Nacuum Thin Films)
Pacific Northwest National Laboratory
Operated by Battelle for the U.S. Department of Energy
The Pacific Northwest National Laboratory (PNNL) in Richland, Washington, has an immediate
need for a senior scientist within the Polymer Multilayer Technologies Group. The candidate
must have a national/international reputation in the field of thin film coatings and deposition
and have demonstrated large-scale process and program development. Strong publication
and presentation record, marketing skills, and project management experience are required.
Demonstrated ability to assemble and supervise multidisciplinary teams to develop innovative
research and novel technology applications. Experience in flat panel display manufacturing
and multilayer coatings on flexible substrates desirable. This position will provide technical
oversight on technical projects in the Polymer Multilayer Group regarding all phases of roll
coating projects from process design through product development and applications. Will pro-
vide team leadership in client interactions, marketing new research, project reviews and other
external presentations, and project management. Will direct efforts to develop new roll coating
processes for increasing market demand. Will direct efforts to characterize thin film optical and
polymer coatings for various projects and will design new coatings.
A PhD degree in physics, chemistry, or materials science, and at least ten years experi-
ence in vacuum roll coating, PVD, plasma polymerization, and GVD technology are required.
Extensive knowledge of polymer chemistry, multilayer optical materials, and polymeric thin
film materials is essential.
Interested persons are encouraged to apply electronically via our external website at
http://www.pnl.gov/hrpublic, referencing requisition \#33800.
PNNL is an Equal Opportunity/Affimative Action Employer and supports diversity in the workplace.
Women, minorities, the disabled and Vietnam-era veterans are encouraged to apply.

\section{FACULTY OPENING \\ School of Chemical Engineering \\ Cornell University}

Comell University invites applications for a tenure-track position in the School of Chemical Engineering. Appointment at any rank is possible depending on the candidate's experience and achievements. The successful candidate should be capable of developing an outstanding research program. Research related to all aspects of materials will be considered, but special emphasis will be placed on polymers and electronic materials.

Applications should include a current CV, a statement of research interests, copies of key publications, and the names of at least three references. Submit applications to Faculty Search Committee, School of Chemical Engineering, 120 Olin Hall, Comell University, Ithaca, NY 14853.

The College of Engineering is an equal opportunity, affirmative action employer committed to employing a highly qualified, diverse faculty. Wornen and minorities are encouraged to apply. 